Int. J. Electrochem. Sci., 15 (2020) 9720 - 9733

International Journal of

ELECTROCHEMICAL

SCIENCE

www.electrochemsci.org

\title{
A Novel Adaptive Extended Kalman Filtering and Electrochemical-Circuit Combined Modeling Method for the Online Ternary Battery state-of-charge Estimation
}

\author{
Cong Jiang ${ }^{1}$, Shunli Wang ${ }^{1,2, *}$, Bin $W^{1}$, Bobobee Etse-Dabu ${ }^{1}$, Xin Xiong ${ }^{1}$ \\ ${ }^{1}$ School of Information Engineering, Southwest University of Science and Technology, Mianyang, \\ 621010, China \\ ${ }^{2}$ Department of Energy Technology, Aalborg University, Pontoppidanstraede 1119220 Aalborg \\ East, Denmark \\ *E-mail: 497420789@qq.com
}

doi: $10.20964 / 2020.10 .09$

Received: 6 May 2020 / Accepted: 30 July 2020 / Published: 31 August 2020

\begin{abstract}
Lithium-ion batteries are used more and more extensively, and the state-of-charge estimation of lithium-ion batteries is essential for their efficient and reliable operation. In order to improve the accuracy and reliability of battery state-of-charge estimation, the Thevenin model was established and the parameters of the least square method model with forgetting factor were used for online identification estimation. To reduce the impact of noise, an adaptive extended Kalman algorithm is developed by combining Sage-Husa adaptive filter with extend Kalman filter algorithm for SOC estimation. The experimental results compared with ampere-time integral method and standard extend Kalman filter method, the improved adaptive extend Kalman filter algorithm has good convergence speed, higher estimation accuracy and stability. The initial SOC error is 5\%, and the root mean square error of extend Kalman filter SOC estimation algorithm is 0.0124 . In contrast, the root mean square error of the proposed adaptive extend Kalman filter SOC estimation algorithm is 0.0109 .
\end{abstract}

Keywords: lithium-ion battery; state-of-charge; adaptive extend Kalman filter; recursive least squares with forgetting factor; online parameters identification;

\section{$\underline{\text { FULL TEXT }}$}

(C) 2020 The Authors. Published by ESG (www.electrochemsci.org). This article is an open access article distributed under the terms and conditions of the Creative Commons Attribution license (http://creativecommons.org/licenses/by/4.0/). 